\title{
Laboratory Test Fasting Status
}

National Cancer Institute

\section{Source}

National Cancer Institute. Laboratory Test Fasting Status. NCI Thesaurus. Code C83309.

An indication or description of whether a laboratory specimen was obtained from a subject that has abstained from food and possibly water for the prescribed amount of time. 